\title{
Saving Travel Time as an Urban Planning Instrument. Case Study: Manizales, Colombia
}

\author{
Carlos A. Moncada ${ }^{1}$, Santiago Cardona ${ }^{2} \&$ Diego A. Escobar ${ }^{2}$ \\ ${ }^{1}$ Universidad Nacional de Colombia, Sede Bogotá, Departamento de Ingeniería Civil y Agrícola, Colombia. \\ ${ }^{2}$ Universidad Nacional de Colombia, Sede Manizales, Departamento de Ingeniería Civil, Colombia \\ Correspondence: Diego A. Escobar, Universidad Nacional de Colombia, Sede Manizales, Departamento de \\ Ingeniería Civil, Colombia. Tel: 887-9300, ext. 50264. E-mail: daescobarga@unal.edu.co
}

\author{
Received: March 21, 2018 Accepted: April 21, $2018 \quad$ Online Published: May 21, 2018 \\ doi:10.5539/mas.v12n6p44 URL: https://doi.org/10.5539/mas.v12n6p44
}

\begin{abstract}
This research explores the benefits of a proposal for urban road infrastructure which aims to improve road connection between northwest and western neighborhoods of the city of Manizales, Colombia, as well as to expand the ring of urban mobility that runs through the city. By calculating the global average accessibility and comparing the current and future situation, by averages of savings gradient, timesaving generated by this alternative are obtained in terms of average travel time. There is evidenced that suggest the road infrastructure proposal would generate savings in the average travel times for the entire city, especially to the neighborhoods located in the area of direct influence.
\end{abstract}

Keywords: accessibility, case study, geostatistics, saving travel time, road infrastructure

\section{Introduction}

The city of Manizales (Figure 1), capital of the department of Caldas, is located in the center of the west of Colombia, in the South American continent where it forms Colombia's Golden Triangle. Located on the central mountain range, it is at 2,150 m.a.s.l. and covers $572 \mathrm{~km}^{2}$ on a steep topography, with strong elevations that generate numerous difficulties and limitations in the urbanization process (Robledo, 1996), as well as in the construction of new road infrastructure. According to the National Administrative Department of Statistics, (DANE, for its acronym in Spanish), Manizales had an estimated population of 398830 in 2017. Its demographics are estimated as follows: women $52 \%$; men $48 \%$; citizens under 20 years $28 \%$ and 60 years or older $16 \%$ (DANE, 2010; Mayoralty of Manizales, 2014). As it is the capital of the department, Manizales attracts people from neighboring municipalities, creating constant synergy in various sectors. Among them: Villamaría the closest municipality $(2 \mathrm{~km})$, which can be accessed by collective public transport and aerial cable system; Neira $(19 \mathrm{~km})$; Chinchiná $(24 \mathrm{~km})$, that houses some important coffee factories headquarters; and Palestine $(31 \mathrm{~km})$, where the Coffee Airport is being built (Escobar \& García, 2011; 2012). 


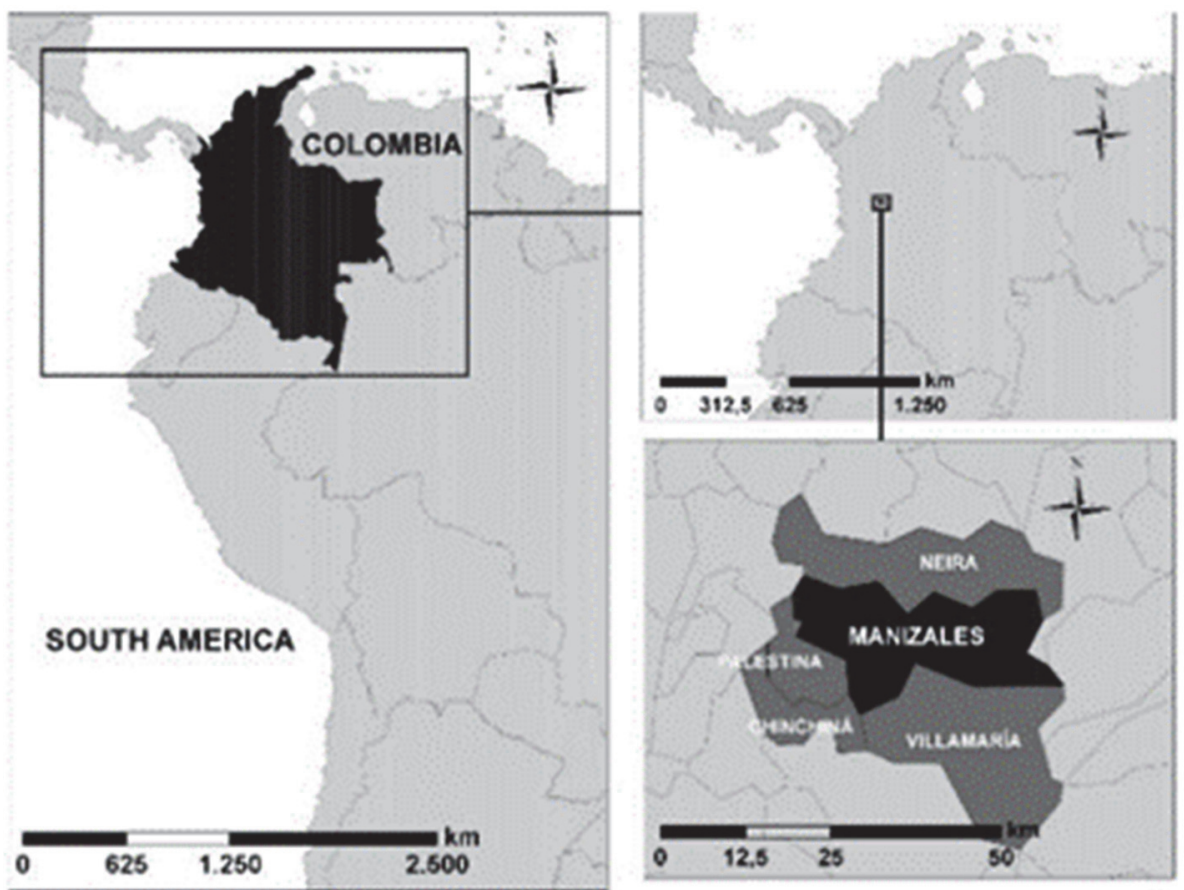

Figure 1. Geographic location of the city of Manizales

The Mayoralty of Manizales has promoted road infrastructure projects through the Valorization Institute of Manizales (INVAMA, for its acronym in Spanish) and the National Institute of Roads (INVIAS, for its acronym in Spanish) in recent years. These aim to improve mobility conditions in the city, reducing traffic and improving travel times, both urban and municipal. These projects follow the national government's efforts seeking to consolidate transport infrastructure and to benefit economic growth and the quality of life of its inhabitants (INVAMA, 2017). Some of the road infrastructure projects promoted by these entities are 'The students' promenade', 'La Carola', 'La Fuente' and 'San Marcel' road intersections, among others (INVAMA, 2018; INVIAS, 2017). Many of these have been financed jointly by national, departmental and local budget, as well as betterment levies promoted by INVAMA. This entity has the responsibility of developing new road infrastructure projects seeking to improve access to the neighborhoods of 'La Francia' and 'Los Alcázares', located in the western part of the city, which, given the topography, has challenging improvement conditions. (INVAMA, 2018).

Territorial accessibility analyses have been used in the last decades as planning instruments to respond to problems derived from the provision of transport systems and territorial management. Records on the matter date back to the 1920s, when it began to be used in North America for studies on transport planning associated with road networks and travel distribution patterns (Mitchell \& Rapkin, 1954; Batty, 2009). However, it was not until the mid-20th century that Hansen (1959) provided its most classical definition: "the potential for interaction opportunities". Later, Dalvi (1978) defined it considering transport and land use: "accessibility indicates the ease with which certain land can be accessed from a specific location using a transport system" (Dalvi, 1978; Monzón de Cáceres, 1988). In the mid-70s, Weibull defined the different mathematical axioms for accessibility calculation including network distribution and measurement opportunities (Weibull, 1976). Accessibility measures have different perspectives, methods and ways to enlarge their analysis due to territorial diversity. Therefore, these studies can be divided by gender, age groups, modes of transport, socio-economic characteristics, etc. (Pirie, 1979; Handy \& Niemeier, 1997).

Accessibility measures are generally analyzed from any of three main approaches: (a) relative accessibility, (b) integral accessibility, and (c) global accessibility. Relative accessibility refers to the measurement between two particular points in the network (Ingram, 1971). Integral accessibility is the measure of access certain point or area has in the network in regards to others in the city (Ingram, 1971). This type of accessibility has been widely studied and different methods have been proposed, such as: measures based on gravity (Hansen, 1959; Carrothers, 2008; Olsson, 2016), based on time or distance (Geurs \& Ritsema van Eck, 2001), and based on accumulated opportunities (Fraser et al., 2017). Finally, global accessibility was described by Geurs \& Ritsema van Eck (2001) 
as infrastructure-based accessibility. It analyzes road infrastructure performance or service, measuring traffic or average speed in the network, obtained as the average of average travel times of all the nodes in a transport infrastructure network (Escobar \& García, 2012). Researchers have used these different approaches to accessibility in order to study it in relation to: sustainable development of transport (Vega, 2011), transportation planning (Talpur, Napiah, Chandio, \& Khahro, 2012), urban public transport (Curtis \& Scheurer, 2015), development of new transport infrastructures (Karou \& Hull, 2014; Escobar \& García, 2011; Escobar \& García, 2012), social equity (Grengs, 2014; Guzmán, Oviedo \& Rivera, 2017), road redirection (Escobar, Duque \& Salas, 2015), temporary analysis of the change in territorial accessibility (Hudeček, 2011), comparison with urban growth (Shoorcheh, Varesi, Mohammadi, \& Litman, 2016), among others.

This research analyzes accessibility based on infrastructure, considering the impact that an alternative road infrastructure generates on the city in terms of average travel times. This alternative seeks to improve access to the neighborhoods 'La Francia' and 'Los Alcázares' located to the west of the city. It will benefit the entire population by connecting the northern and western sectors, completing the ring road mobility of the city. By calculating savings gradient, an a priori - a posteriori comparative analysis of global average accessibility was carried out in the city's road network. The research methodology, main results, and conclusions are then discussed.

After the introduction, the research methodology is exposed and the main obtained results will be mentioned. Lastly, the conclusions gotten as the result of the research work will be shown.

\section{Method}

The research methodology (Figure 2) consisted of four consecutive stages and a preliminary data entry, described below:

\subsection{Input Data}

As input data, the following are configured: i) georeferenced transport infrastructure network loaded with operational data; and ii) neighborhood division data layer loaded with official sociodemographic data. Based on a previous study conducted by Escobar \& García (2012) called 'Diagnóstico de la movilidad Urbana de Manizales', it was possible to obtain the georeferenced road network with data such as average slope and average speed in the arcs. Likewise, it was possible to obtain the neighborhood division layer of the city, which, in addition to the sociodemographic data, was supplemented with the socio-economic stratum data, which is a measure of the social and economic conditions of each neighborhood (Perilla, Escobar \& Cardona, 2018).

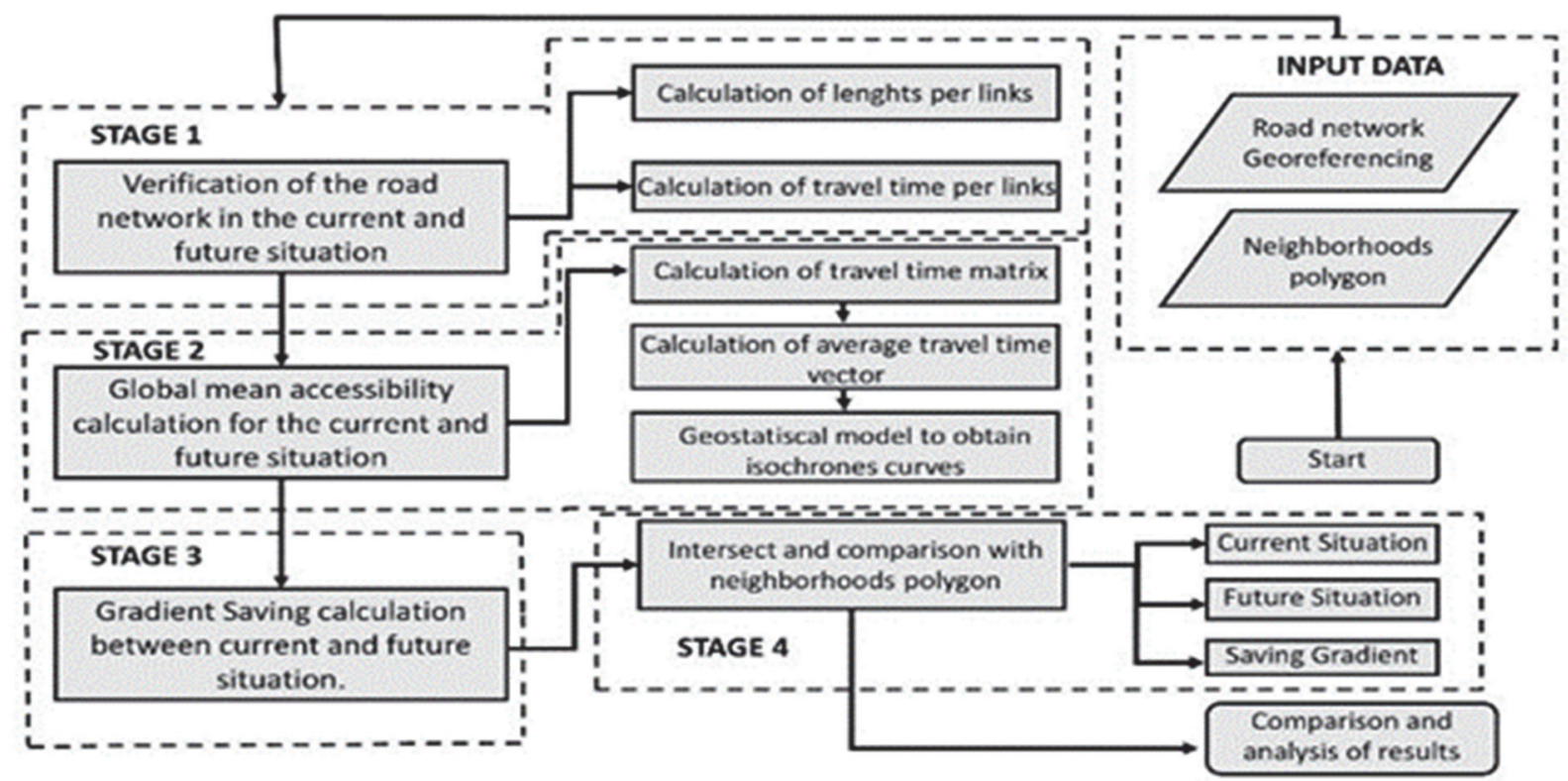

Figure 2. Research methodology

\subsection{Verification of the Road Network in the Current and Future Situation}

This stage corresponds to the verification of the transport infrastructure network in the current situation (Figure 3). Based on the infrastructures network of the entrance transport, it is updated, including road infrastructure works 
and the changes made in directionality until 2017.

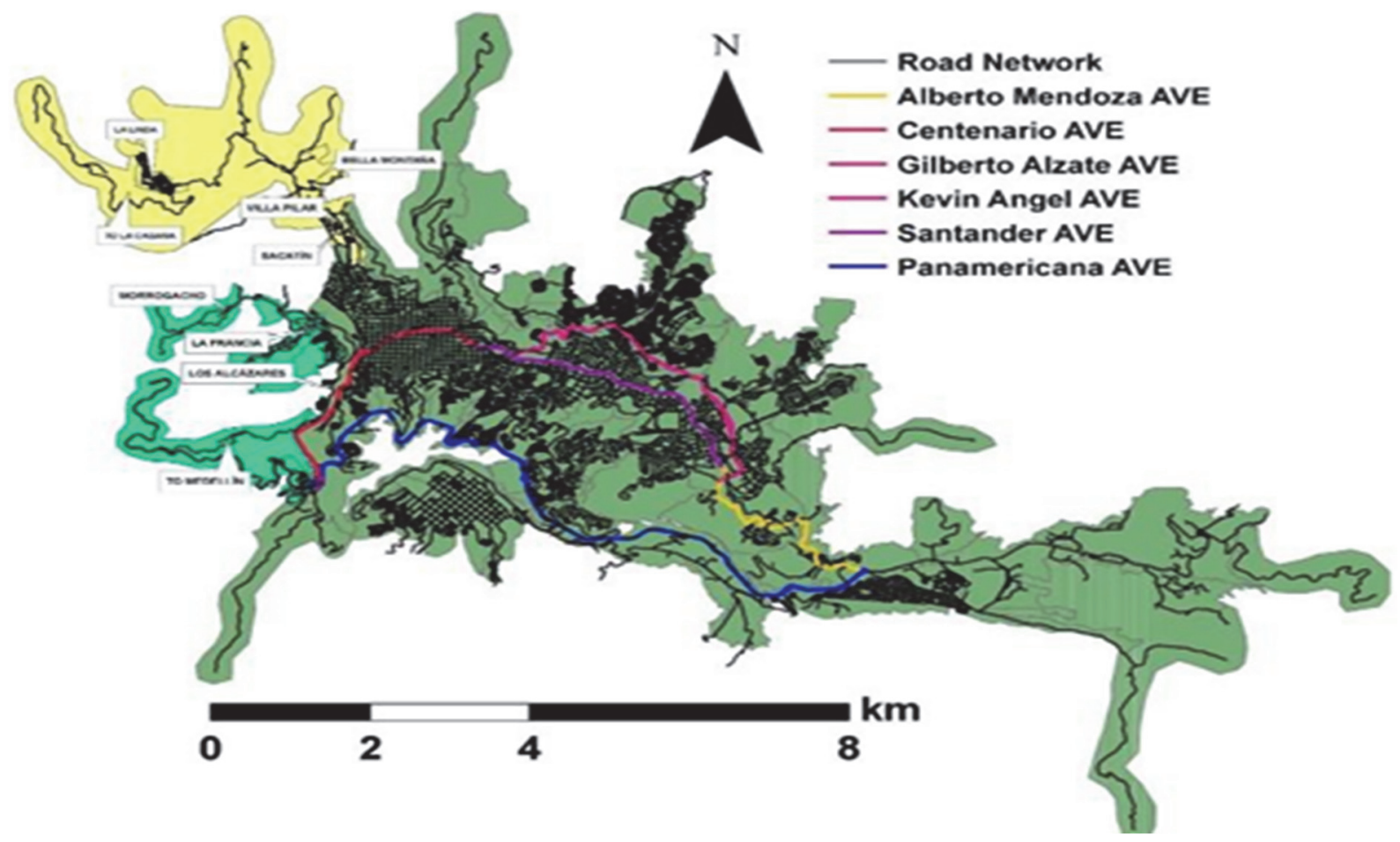

Figure 3. Current road network

Current transport infrastructure network has a length of $672 \mathrm{~km}$. approximately $10 \%$ of it are main roads integrating the city's mobility support rings. Figure 3 shows the neighborhoods that will directly benefit from the construction of the proposed infrastructural alternative. The western sector (zian color in Figure 3), has a population of 5,531 inhabitants distributed in the neighborhoods 'La Francia' (16\%), 'Los Alcázares' (61\%), 'Morrogacho' (23\%) and the areas that are located at the exit towards the city of Medellín (second most important city in Colombia after its capital, Bogotá). The northern sector registers almost twice the population of the western sector, reaching 10,690 inhabitants, distributed in the neighborhoods 'Villa Pilar' (57\%), 'Sacatín' (6\%), 'La Linda' (35\%), 'Bella Montaña' $(2 \%)$ and areas that are in the exit towards 'La Cabaña', rural zone of the municipality of Manizales.

The mobility support ring is shown in the current situation. It aims to generate a connection around it through road corridors that have an operating speed higher than the average recorded in the rest of network arcs. The Avenues Panamericana (south/blue line), Alberto Mendoza (east/yellow line), Kevin Angel (north/red line), Gilberto Álzate (center/line fuchsia), and Centenario (west/purple line) make up the mobility support ring. The Panamerican Avenue is categorized as a 'national highway' and has a suburban functionality. It is a variant for load vehicles that go to center or southern regions of the country. Its geometric characteristics allow vehicles to reach high speeds. Alberto Mendoza Avenue connects areas of high socioeconomic strata to the east with the center and west of the city. Kevin Ángel Avenue supports the automotive flows that come from sectors of medium and low strata located on the north and go to the east, center or west of the city. Gilberto Álzate Avenue crosses the center of the city in an east-west direction and vice versa with a multiplicity of land uses. Centenario Avenue runs through the west of the city, closing the main mobility support ring of the city. Figure 4 shows the future situation of the transport infrastructure network. It includes the alternative proposed as a northwestern solution, seeking to improve the connection among neighborhoods in the northern and western region of the city, as well as connecting them with the mobility support ring previously exposed. 


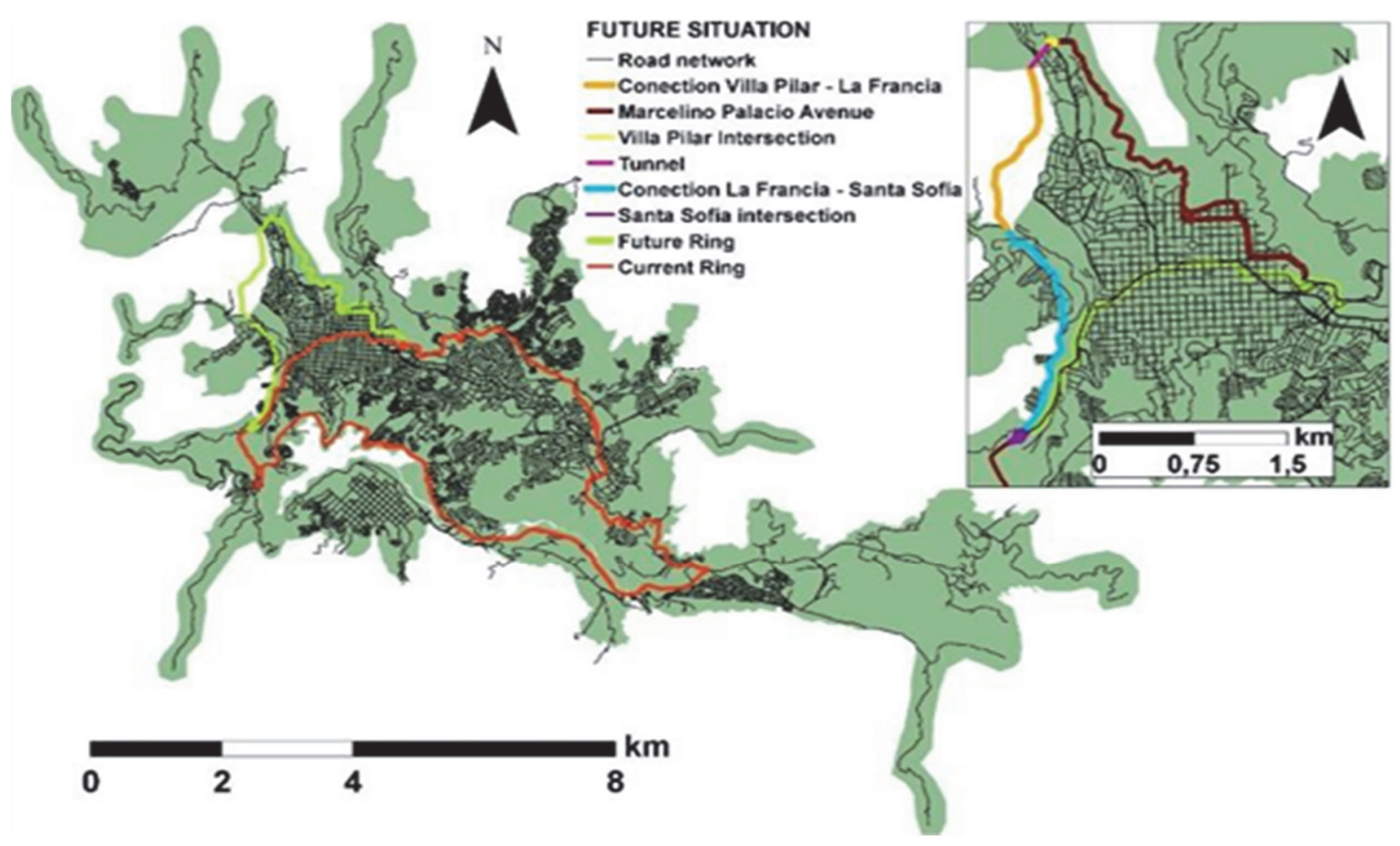

Figure 4. Future road network

The proposed alternative seeks to widen the mobility ring by averages of the following works:

-Construction of the intersection in the access to 'Santa Sofía' to allow continuity in vehicular flow from the Centenario Av. and diminishing conflict among vehicles.

-Improvement of geometrical conditions of the road connecting 'La Francia' and 'Santa Sofía' neighborhoods.

-Construction of a $1.6 \mathrm{~km}$ road alongside a $270 \mathrm{~m}$ tunnel connecting 'La Francia' and 'Villa Pilar' (blue line).

These interventions connect the north with current Marcelino Palacio Av., which has been constructed recently (INVAMA, 2013). Besides the proposed interventions, and the Marcelino Palacio and Gilberto Álzate Avenues, a new mobility ring would be created in the north of the city, in connection with the first mobility support ring in the city. Once the current and future transport infrastructure networks were validated, link longitude and travel times between nodes were calculated using geographic information systems (GIS).

\subsection{Global Average Accessibility Calculation for the Current and Future Situation}

From travel times between each pair of nodes (tv) in minutes, the average travel times between nodes $i$ and $j$ of the transport infrastructure network are calculated, generating a matrix. The tv between different start nodes $i$ and arrival nodes $\mathrm{j}$ are calculated by the Dijkstra algorithm, better known as the minimum path algorithm, which determines the shortest path between a node of origin $\mathrm{O}$ and destination node $\mathrm{D}$, as long as there is connection, minimizing a certain variable. In the case of transport networks and for accessibility calculations, the variable corresponding to the tv on the arcs is minimized (Dijkstra, 1959; Sallán et al., 2002). This algorithm is immersed in the "Multiple paths" tool of the TRANSCAD program, which was used to calculate the travel time matrix. After having the travel time matrix, calculate the average travel time vector $(\overline{T v i})$ of initial nodes (i), which is quantified by equation (1), where (tvij) averages the travel time it takes for node $\mathrm{i}$ to reach node $\mathrm{j}$ and where $n$ is the number of nodes.

$$
\overline{T v i}=\frac{\sum_{j=1}^{n} t v_{i j}}{n-1} \quad i=1,2,3, \ldots, n \quad j=1,2,3, \ldots, n
$$

Once the vector of average travel time between nodes in the transport infrastructure network were obtained, a geostatistical calculation was carried out, obtaining isochrones curves of global average accessibility for the current and future situation. The ordinary Kriging model, which is a spatial interpolation method through the linear combination of random variables, was used (see (2)). As a correlation function, the linear semi-variogram (see (3)), 
which uses the shortest distance criterion achieving better predictions for short distances between nodes, was chosen (Giraldo, 2002; Wackernagel, 2003). This method has previously been used by researchers for issues such as demand prediction of public transport systems (Prasetiyowati, Imrona, Ummah, \& Sibaroni, 2016).

$$
\begin{gathered}
T v_{o}=\lambda_{1} T v_{1}+\lambda_{2} T v_{2}+\lambda_{3} T v_{3}+\lambda_{4} T v_{4}+. .+\lambda_{n} T v_{n}=\sum_{i=1}^{n} \lambda_{i} T v_{i} \\
\overline{\gamma_{(h)}}=\frac{\sum\left(Z_{(x+d)}-Z_{(x)}\right)^{2}}{2 n}
\end{gathered}
$$

$\lambda i$ represents original value weights and is calculated as a function of the distance between nodes and places where the prediction is intended $T v_{o}$ represents the value of travel time to be predicted and $T v_{i}$ represents average travel times known from the time vector $\overline{\gamma_{(h)}}$ represents the linear semivariogram, while $Z_{(x)}$ refers to the predicted value, and $\left.Z_{(x+d)}\right)$ ) indicates a sample value separated by a distance $\mathrm{d}$, and $\mathrm{n}$ is the number of couples separated by said distance (Perilla et al., 2018).

\subsection{Gradient Saving Calculation between the Current and Future Situation}

After obtaining isochrones curves of global average accessibility for the current and future situations, the savings gradient in average travel times between both scenarios was calculated. A percentage for these numbers in both scenarios was obtained. Percentage saving gradient (\%SG) (see (4)) relates the global average accessibility results of the current (GMAc) and future (GMAf) situation (Perilla et al., 2018).

$$
\% S G=\left(\frac{G M A C-G M A f}{G M A C}\right) * 100
$$

\subsection{Coverage Analysis for the Current and Future Situations, and Percentage Gradient of Average Travel Time}

Lastly, isochrones curves of global average accessibility and sociodemographic information layer, population, socioeconomic stratum, number of dwellings, area, etc. were related, in order to obtain coverage percentages of said variables, as isochrones curves value increase. The percentage ojivas of spatial coverage were then calculated. This procedure was carried out for the current and future situations, and for percentage gradient of average travel time saving, which allowed coverage comparisons and defined the impact generated given the insertion of said transport infrastructures in the city of Manizales.

\section{Results and Discussion}

\subsection{Global Average Accessibility for the Current and Future Situation}

Figure 5 shows isochrones curves of global average accessibility for the current situation, finding that along the mobility support ring that crosses the city from west to east in the north is the lower curve average travel time: up to 25 minutes representing the best global average accessibility of the city. The southern sector of the mobility support ring is covered by 30 and 35-minute curves. The curves expand more in a west-east direction than in a north-south direction, which clearly demonstrates the connection deficiencies in that sense and is related to the fact that the city's greatest infrastructural development has been generated in the longitudinal direction (west-east) given its topography. In the eastern part of the city there are areas that reach up to 55 minutes of average travel time, although they do not represent the highest average travel time recorded, which is identified in the northwestern part of the city, averaging up to 70 minutes in travel time. The sector where the new transport infrastructure is proposed can be covered in average travel times of more than 40 minutes, up to 65 minutes in the area located to the west. Therefore, the sector of study is precisely the one that registers the worst accessibility conditions in the current situation. 


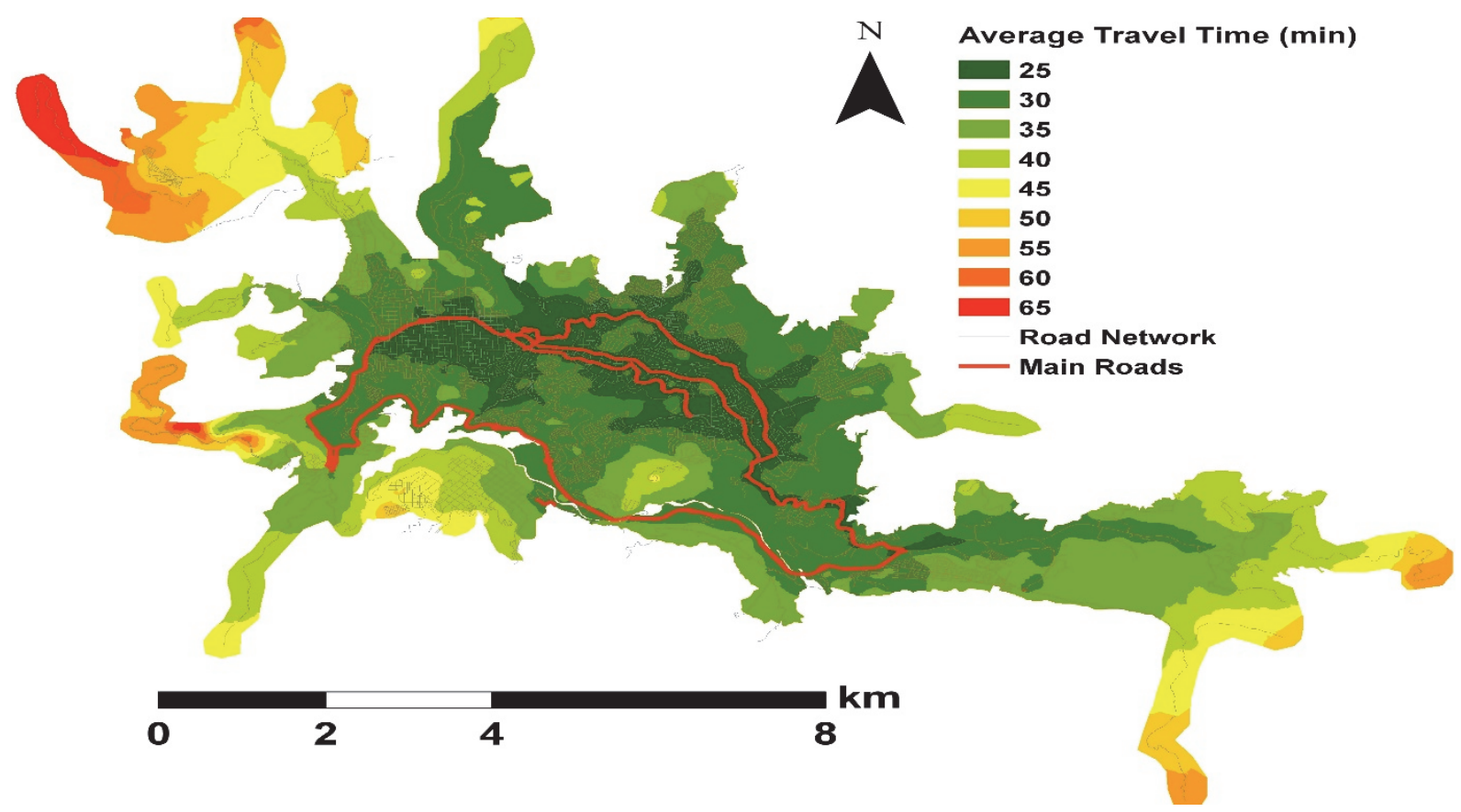

Figure 5. Isochrones curves for the current situation

Figure 6 shows the result of the isochrones curves of global average accessibility for future situation of the road network, including the proposed alternatives described in section 2.2. In the isochrones curve, less than 25 minutes is $14 \%$ of the total area of the city (5,868 hectares), $1 \%$ more than the current situation. $31 \%$ of the city area is represented in the 30-minute isochrones curve, with the largest area covered. Northern and western zones of the city benefit directly from the alternative road as the average travel times decreases. For instance, the isochrones curve for the exit towards the northwest, is now of 70 minutes, while it is estimated in 65 minutes in the future scenario, decreasing 5 minutes in average travel times. The Southwest exit also obtained a benefit in reducing its average travel time with isochronous curves shifting from 65 minutes to 55 minutes.

The Figure 7 shows the relationship between isochrones curves of global average accessibility of the current and future situation and the corresponding percentages of the population covered. For the current situation, $75 \%$ of the population is covered with an average travel time of less than 30 minutes. Only $10 \%$ of the population perceives average travel times of 40 minutes. On the other hand, the future scenario decreases average travel times, achieving $78 \%$ coverage of the population for average travel times of less than 30 minutes.

Figure 8 shows the relationship between percentage coverage of population and isochrones accessibility curves for the current situation according to socioeconomic strata. It was found that in the current situation, the population of stratum 5 had the best accessibility conditions given the operational characteristics of the transport infrastructure network, while the strata with the worst accessibility conditions are precisely those with the lowest economic capacity: 1 and 2. For example, to cover $50 \%$ of the population according to the stratum: in the case of stratum 5 (14,052 inhabitants), approximately 23 minutes of average travel time should be invested; while for stratum 1 (32,360 inhabitants) and 2 (104,935 inhabitants) 26 and 28 minutes must be invested respectively. The entire stratum 5 population is covered with average travel times of up to 30 minutes, while for the other strata said average travel time increases to values between 40 and 55 minutes. 


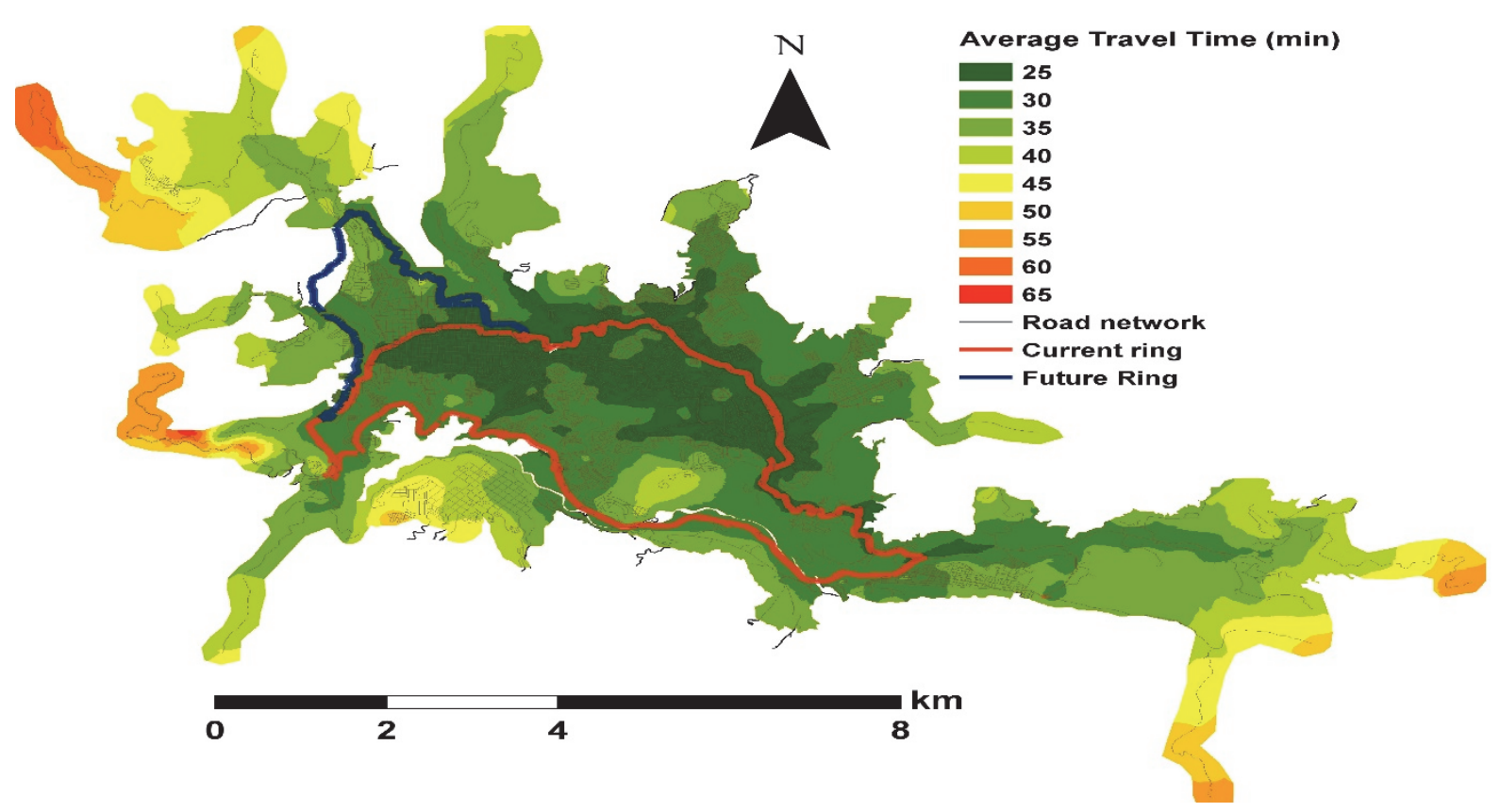

Figure 6. Isochrones curves for the future situation

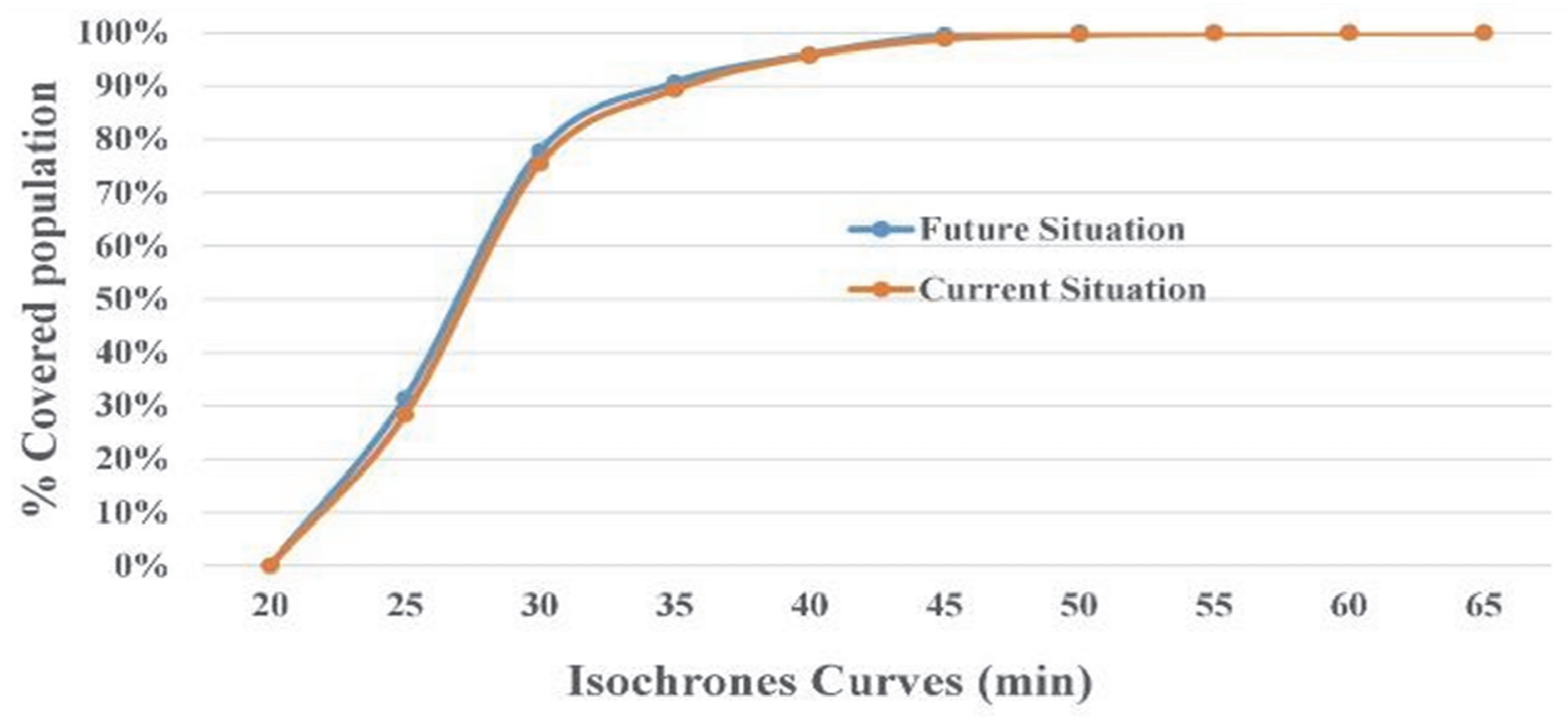

Figure 7. Relation between percentage of covered population and isochrones curves for the current and future situation

Figure 9 shows the relationship between population percentage covered and isochronous accessibility curves for the future situation according to socioeconomic strata. There is an improvement in the conditions of global average accessibility as a result of the proposed infrastructural alternative. Stratum 1 has $3 \%$ more population covered by the isochrone up to 35 minutes; stratum 2's entire population is covered in the isochronous curve of up to 50 minutes showing a 5-minute improvement, as stratum 3 has shown. Stratum 3 also had its entire population in the isochronous curve from 50 minutes to 45 minutes where there was an improvement of $2 \%$ in the percentage of population coverage for the isochronous curve of up to 30 minutes. 


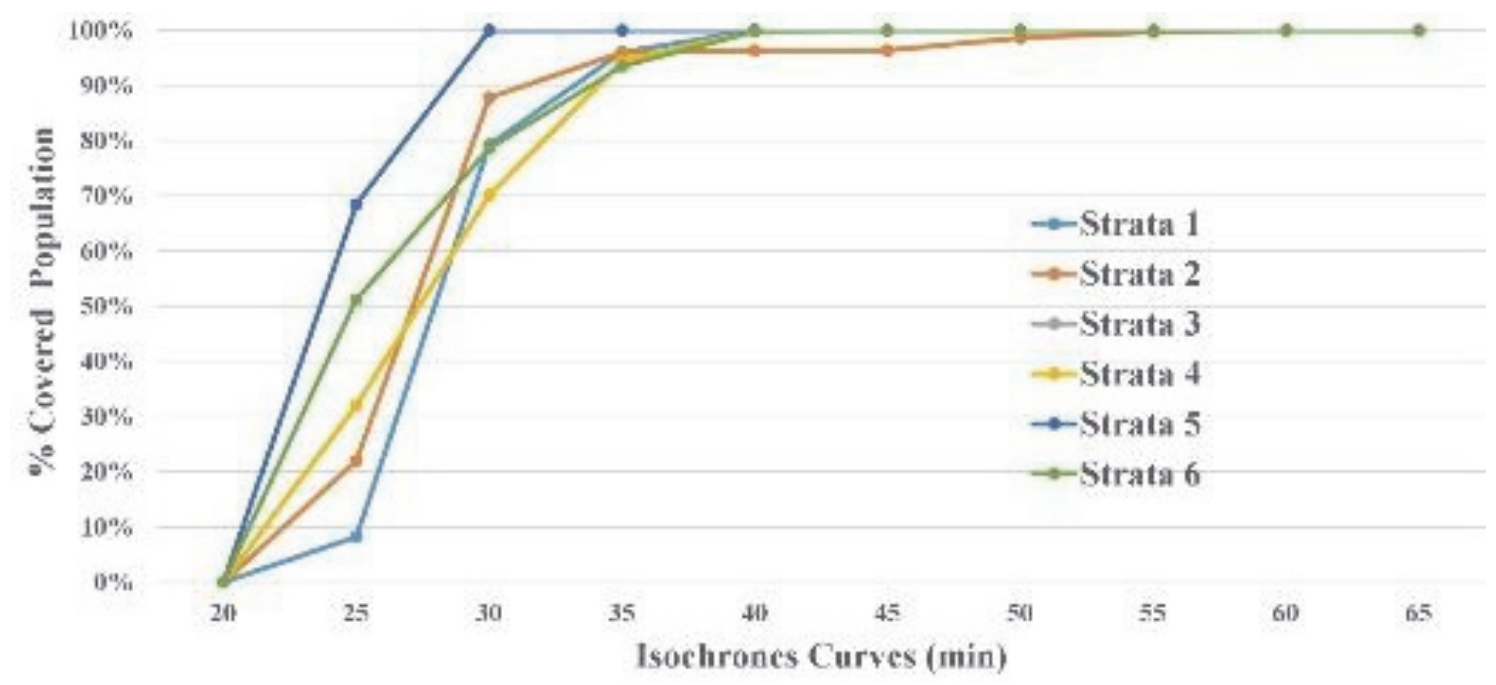

Figure 8. Relation between percentage of covered population, isochrones curves and socio economic strata for the current situation

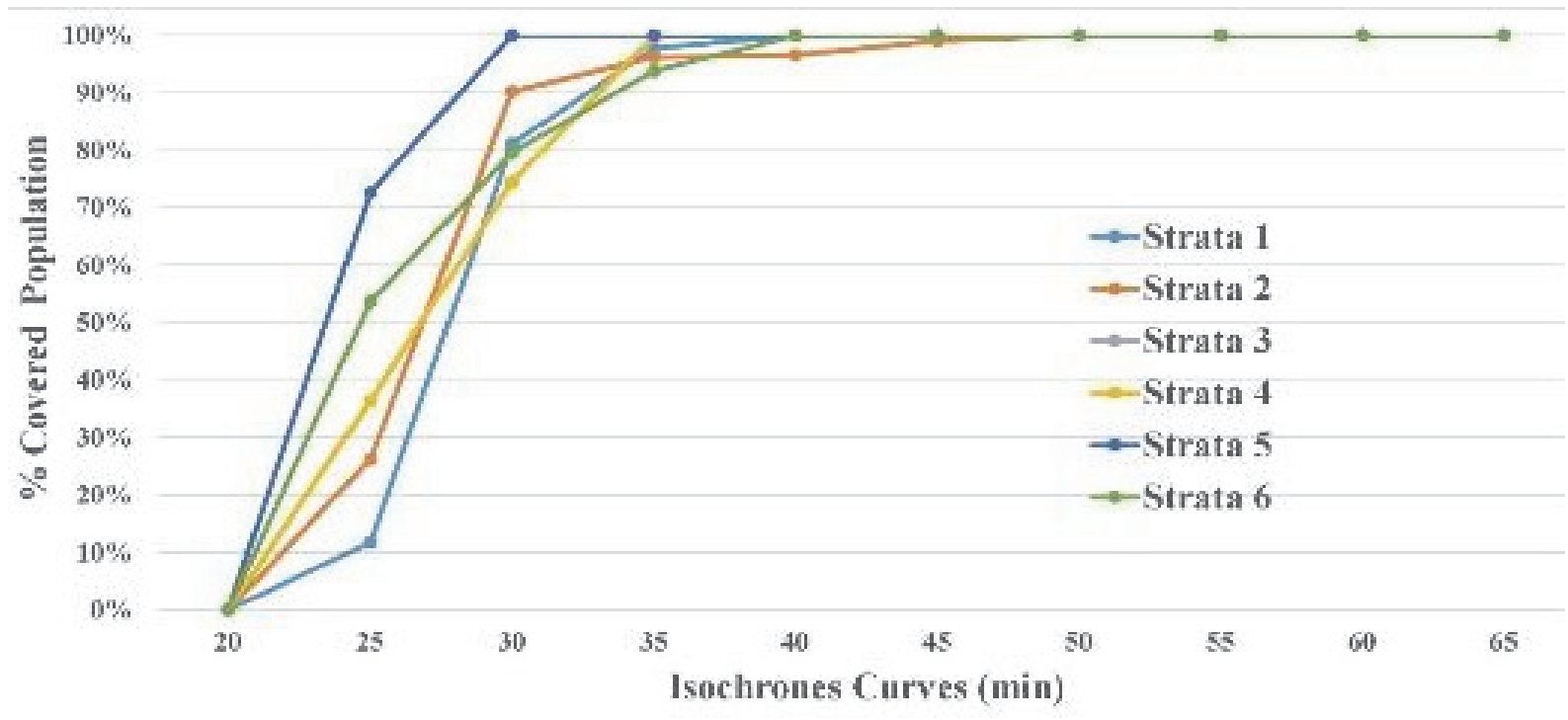

Figure 9. Relation between percentage of covered population, isochrones curves and socio economic strata for future situation

Stratum 4 showed improvement of 5 minutes for the entire population, going from an isochrone curve of 40 minutes in the current situation to 35 minutes in the future situation. Furthermore, there was an increase of $4 \%$ in the covered population for the isochronous curve of 30 minutes. For stratum 6 , the future situation gets $1 \%$ more population coverage for the average travel time of up to 30 minutes. Finally, stratum 5 also improves its conditions of global average accessibility since 5\% more of the population is located in the isochronous curve of up to 25 minutes. This last one has the largest population in this isochronous curve.

\subsection{Saving Gradient (\%) between the Current and Future Situation}

Figure 10 shows the percentage savings obtained by comparing the current and future situations. A large part of the city is benefited, where $23 \%$ of the total city area registered savings of up to $5 \%$ in the average travel time, while $12 \%$ of the area receives savings of up to $10 \%$, mainly concentrated in the southwest sector. Analyzing the population, it was found that $8 \%$, concentrated in the north-western sector, reaches up to $15 \%$ savings in average travel times. The greatest time savings are reached in the 'Bella Montaña' neighborhood and the surroundings of 
the connection between 'Villa Pilar' and Avenida Colón, where 3\% of the area reaches up to $17.5 \%$ savings in average travel time, with a maximum savings of up to $25 \%$.

Figure 11 shows the relationship between population and area coverage and the gradient of savings generated, where $2 \%$ of the population $(8,500$ inhabitants) perceives savings in average travel times of up to $10 \%$ regarding the current situation. Likewise, $1 \%$ of the population reaches up to $15 \%$ of savings, which continues to increase, reaching $25 \%$ in areas of difficult access in the city and with few population records.

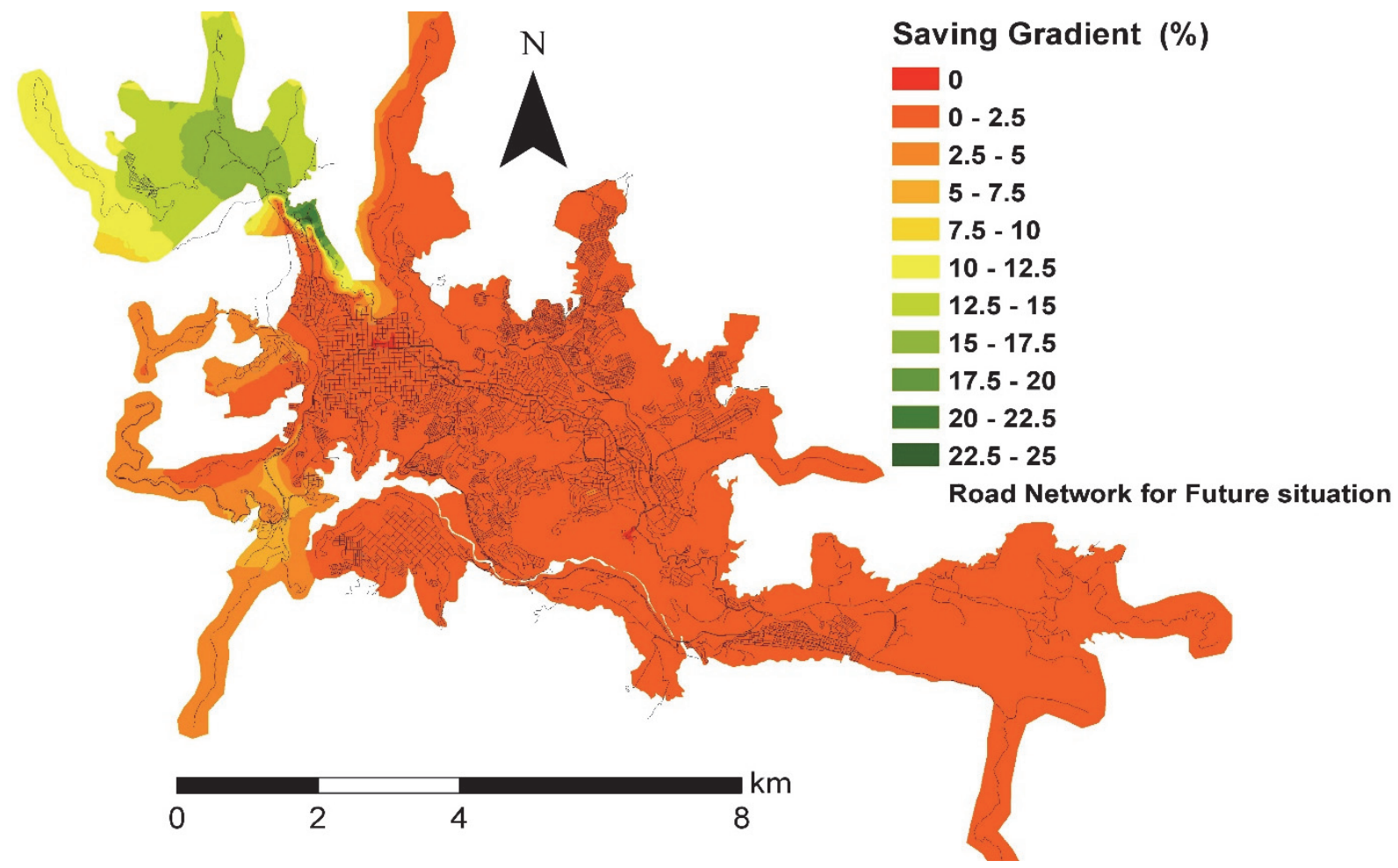

Figure 10. Saving Gradient (\%) between isochrones curves for the current and future situation

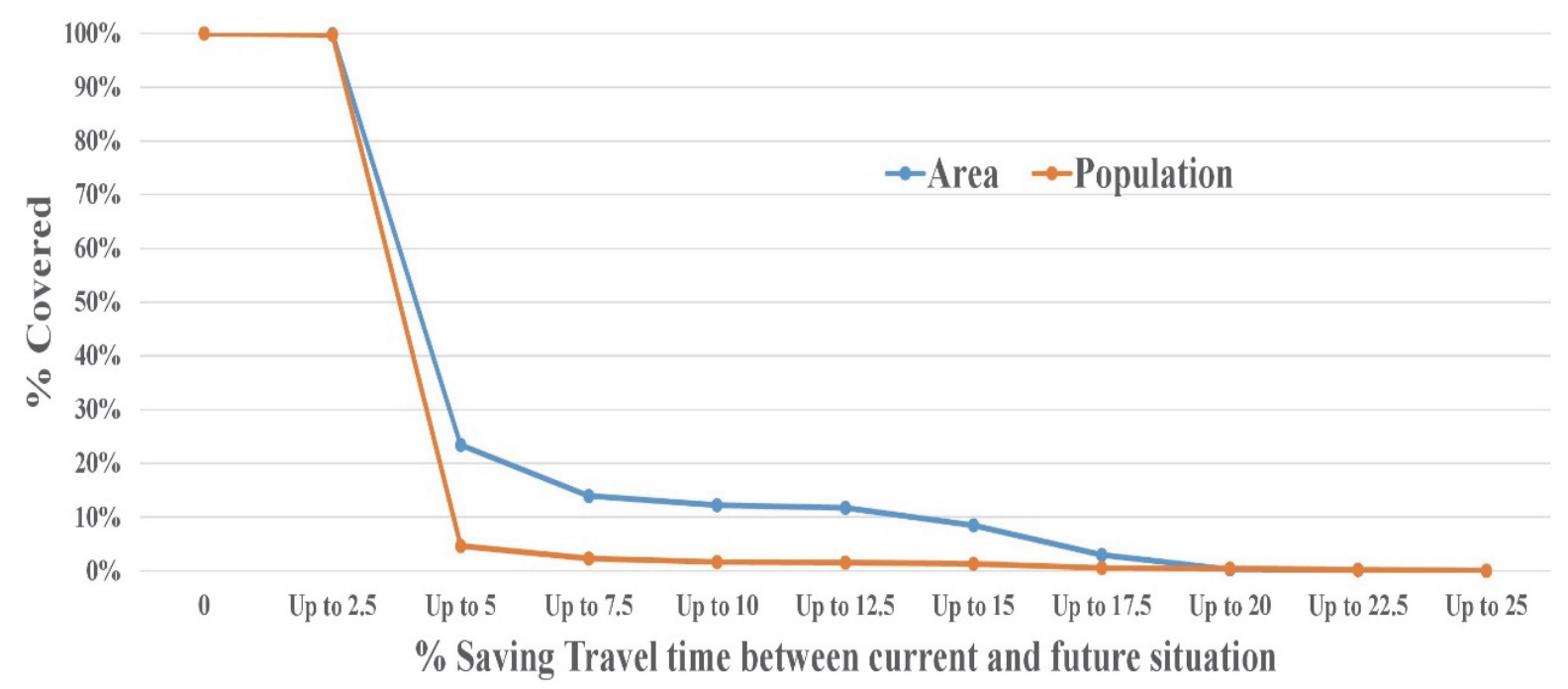

Figure 11. Relation between \% of covered population and area and gradient saving (\%)

Figure 12 shows the relationship between population percentage covered and the percentage savings gradient obtained given the proposed infrastructure, according to the socioeconomic strata. The whole population, indistinct to its stratum, saves up to $2.5 \%$ in average travel time. Even so, the stratum 4 is the one that perceives the highest 
percentage of savings, for $11 \%$ of its population reaches up to $5 \%$ of savings in average time of travel, a range of savings that grows to reach $20 \%$ for $3 \%$ of the population, which represents a benefit for approximately 200 families in the city. For this same savings interval, strata 1 and 2 reach $5 \%$ of the covered population. On the other hand, stratum 2 receives a saving of up to $12.5 \%$ for $4 \%$ of its population, representing approximately 3000 inhabitants.

Finally, Figure 13 compares population percentage covered and savings derived from transport infrastructure proposed for the neighborhoods directly benefited located in the northwest and west of the city.

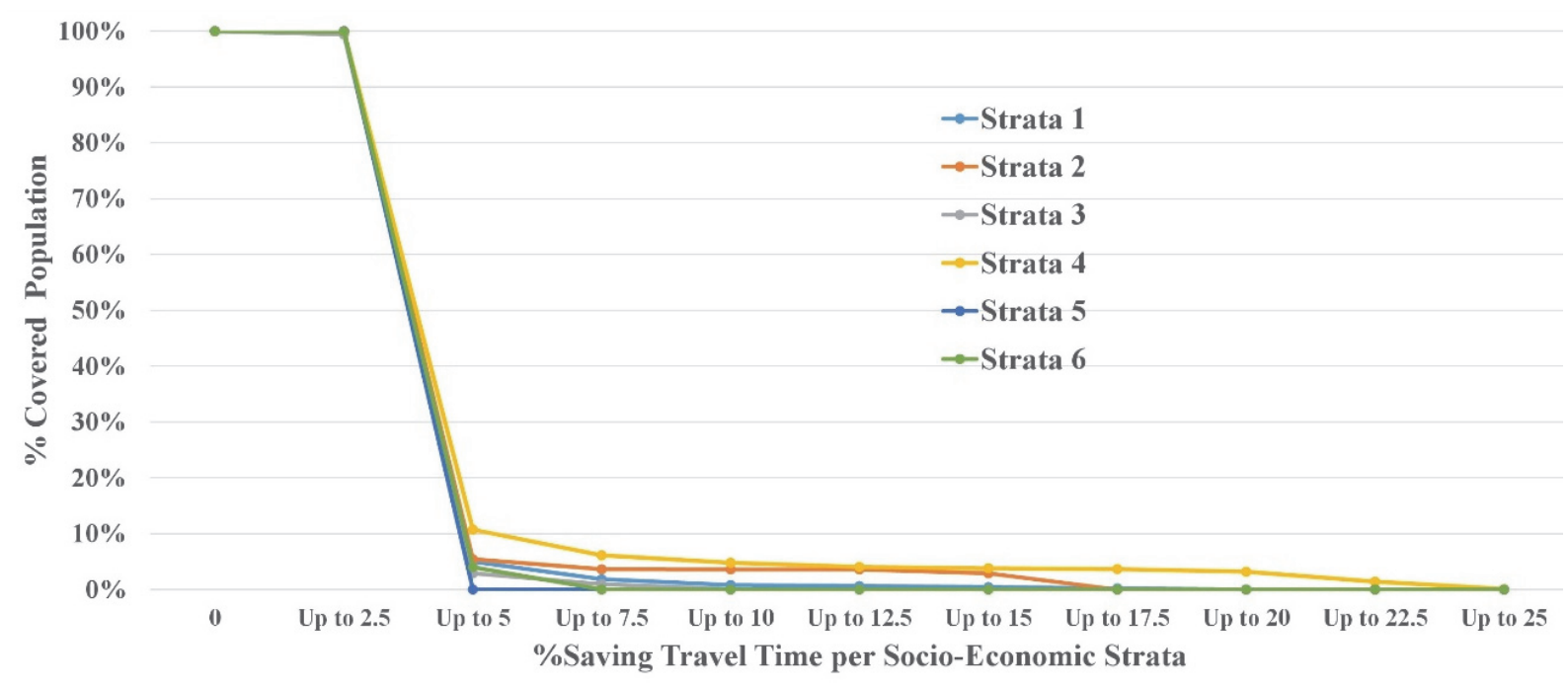

Figure 12. Relation between percentage of covered population and percentage of saving gradient per socio economic strata on Manizales

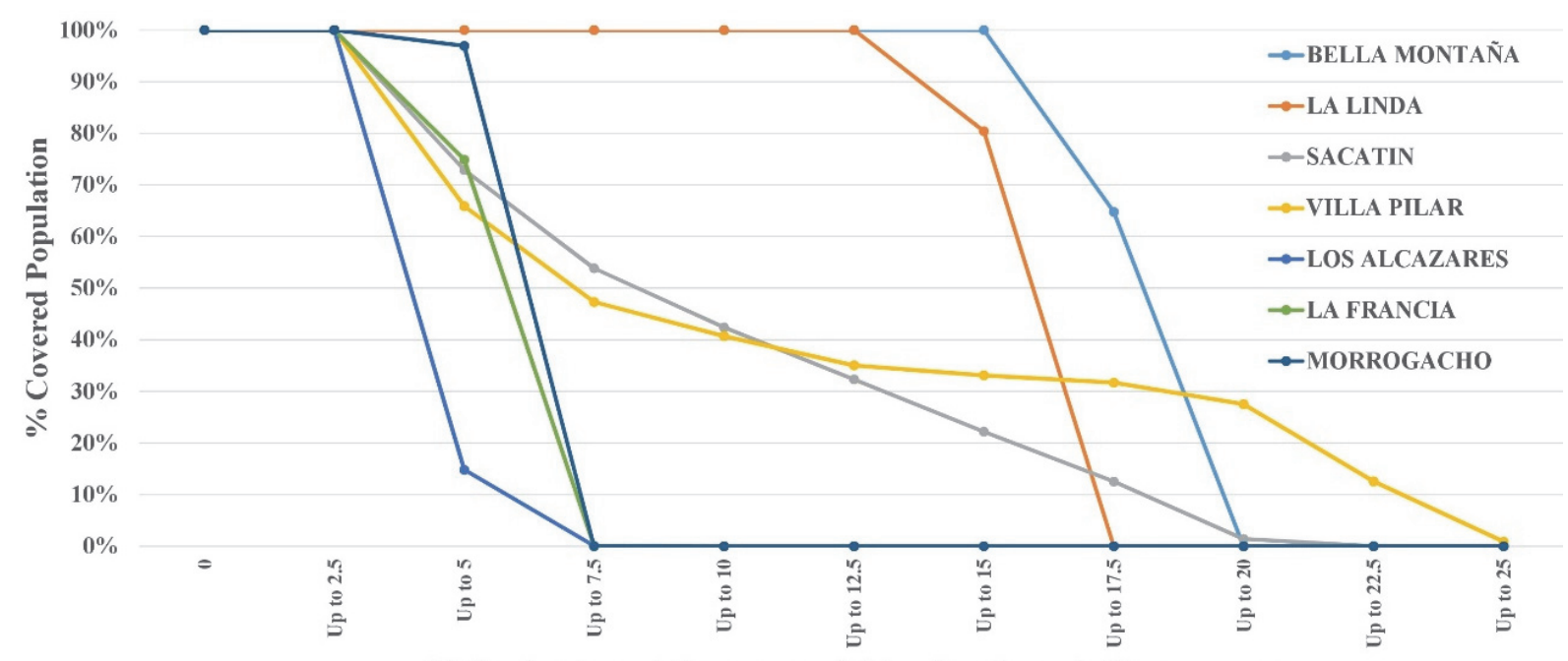

$\%$ Saving travel time per neighborhoods on influence zone

Figure 13. Relation between percentage of covered population and saving gradient per neighborhoods on influence zone (\%)

Considering the northwestern districts, 'Bella Montaña' neighborhood was found to save up to $15 \%$ on the average travel time for $100 \%$ of its inhabitants; $65 \%$ of its inhabitants decreased their travel times in up to $17.5 \%$. The entire 'La Linda' population saved up to $12.5 \%$. In the neighborhoods of 'Villa Pilar' and 'Sacatin', savings reached up to $2.5 \%$ to $100 \%$ of its inhabitants, yet $33 \%$ of the population in 'Villa Pilar', $22 \%$ in 'Sacatin', and $80 \%$ in 'La Linda' saved up to $15 \%$ saving on average travel times. In the western sector, all inhabitants refered savings in average travel times of up to $2.5 \%$; in particular, $75 \%$ of the population of 'La Francia' saved up to 5\%, while in 'Los Alcázares' the percentage reached 15\%. Finally, the 'Morrogacho' district is the Western Sector most 
benefited, since $97 \%$ of the population perceived savings of up to $5 \%$.

\section{Conclussions}

The proposed road infrastructure alternative to improve connection among neighborhoods in the northwestern and western areas of the city of Manizales, generates verifiable benefits in terms of average travel times, since the entire city's population would reduce their average travel times in $2.5 \%$. This saving percentage can reach up to $10 \%$ to $2 \%$ of the population, benefiting about 8,200 inhabitants (approximately 200 families).

The districts of the northwest sector, 'La Linda' and 'Bella Montaña' neighborhoods saved up to $12.5 \%$ in average travel times, directly benefiting approximately 4000 inhabitants. In 'Villa Pilar' and 'Sacatín', savings reach 10\% to $41 \%$ and $42 \%$ of the populations each. Districts of the western sector benefited with road works of the intersection access to the Southwest, adjacent to the of 'Santa Sofía Hospital'. In addition, in 'La Francia', 75\% of the population saved up to $5 \%$ on average travel times. Verifying mobility benefits perceived by the population, the establishment of betterment levies for financing may be established.

The savings gradient calculated by measuring global media accessibility for two different transport network scenarios is an effective tool to assess benefits in terms of savings in average travel times when planning infrastructure projects that generate solutions for access and connection issues among sectors through the construction and improvement of infrastructure.

The current research method could be improved by utilizing population projections, analyzing the future coverage scenarios as the new infrastructure is being used. Moreover, this tool could be complemented with a valorizing fee as well as an increasing of capital gain taxes in the influenced area, finding a financing alternative for this purpose.

\section{Acknowledgments}

The authors thank the research center of sustainable mobility of the National University of Colombia, Manizales campus.

\section{References}

Alcaldía de Manizales. (2014). Información General. Retrieved from: http://www.manizales.gov.co/Contenido/Alcaldia/24/informacion-general

Batty, M. (2009). Accessibility: In search of a unified theory. Environment and Planning B: Planning and Design, 36(2), 191-194. http://doi.org/10.1068/b3602ed

Carrothers, G. A. P. (2008). Journal of the American Institute of Planners an Historical Bedew of the Gravity and Potential Concepts of Human Interaction, (March 2015), 37-41. http://doi.org/10.1080/01944365608979229

Curtis, C., \& Scheurer, J. (2015). Performance measures for public transport accessibility: Learning from international practice. Journal of Transport and Land Use, 10(1), 1-26. http://doi.org/10.5198/jtlu.2015.683

Departamento Administrativo Nacional de Estadística - DANE (2010). Proyecciones de población total por sexo $y$ grupos de edad de 0 hasta 80 y más años (2005 - 2020). Retrieved from http://www.dane.gov.co/index.php/estadisticas-por-tema/demografia-y-poblacion/proyecciones-depoblacion

Dalvi, M. Q. (1978). Behavioural modelling accessibility, mobility and need: Concepts and measurement. Behavioural travel modelling, 639-653.

Dijkstra, E. W. (1959). A note on two problems in connexion with graphs. Numerical Mathematics, 1(1), 269-271. https://doi.org/10.1007/BF01386390

Escobar, D. A., \& Garcia, F. J. (2011). Impacto de un sistema de transporte tipo Cable sobre la movilidad urbana. Caso Manizales (Colombia). Avances Investigación En Ingeniería, 8(1), 92-98. Retrieved from http://www.unilibre.edu.co/revistaavances/avances-8-1/r8-1_art11.pdf

Escobar, D. A., \& García, F. J. (2012). Análisis de priorización de proyectos viales: caso Manizales (Colombia). (First Edition). Manizales. Universidad Nacional de Colombia. Retrieved from: http://www.bdigital.unal.edu.co/10941/6/9789587611298.2012.pdf

Escobar, D. A., \& Garcia, F. J. (2012). Diagnóstico de la Movilidad Urbana de Manizales (First Edition). Manizales. Universidad Nacional de Colombia. Retrieved from: http://www.uneditorial.net/uflip/Diagnostico_de_movilidad_urbana_de_manizales/pubData/source/Diagnos tico_de_movilidad_urbana_de_manizales.pdf

Escobar, D. A., Duque, J. P., \& Salas, A. (2015). Accesibilidad como herramienta de planeación urbana. Caso de 
estudio : Redireccionamiento vial en Riosucio (Caldas - Colombia). Avances Investigación En Ingeniería, 11(2), 9-18. Retrieved from: http://www.unilibre.edu.co/revistaavances/edicion-11-2/accesibilidad-comoherramienta-de-planeacion-urbana-caso-de-estudio-redireccionamiento-vial-en-riosucio-caldascolombia.pdf

Fraser, A. M., Chester, M. V., Eisenman, D., Hondula, D. M., Pincetl, S. S., English, P., \& Bondank, E. (2017). Household accessibility to heat refuges: Residential air conditioning, public cooled space, and walkability. Environment and Planning B: Urban Analytics and City Science, 44(6), 1036-1055. http://doi.org/10.1177/0265813516657342

Geurs, K. T., \& Ritsema van Eck, J. (2001). Accessibility measures: review and applications. Evaluation of accessibility impacts of land-use transportation scenarios, and related social and economic impact. RIVM Report, 787, 1-265. Retrieved from: https://rivm.openrepository.com/rivm/handle/10029/9487

Giraldo, R. (2002). Introducción a la geo estadística: Teoría y aplicación. Universidad Nacional de Colombia, Bogotá, Colombia.

Grengs, J. (2014). Nonwork Accessibility as a Social Equity Indicator. International Journal of Sustainable Transportation, 9(1), 1-14. http://doi.org/10.1080/15568318.2012.719582

Guzman, L. A., Oviedo, D., \& Rivera, C. (2017). Assessing equity in transport accessibility to work and study: The Bogotá region. Journal of Transport Geography, 58, 236-246. http://doi.org/10.1016/j.jtrangeo.2016.12.016

Hansen, W. G. (1959). How accessibility shapes land use. Journal of the American Institute of planners, 25(2), 7376. https://doi.org/10.1080/01944365908978307

Handy, S. L., \& Niemeier, D. A. (1997). Measuring Accessibility: An Exploration of Issues and Alternatives. Environment and Planning A, 29(7), 1175-1194. http://doi.org/10.1068/a291175

Hudeček, T. (2011). Analysis of the Accessibility of Prague in Czechia in the 1918-2020 Period. Hrvatski Geografski Glasnik, 73(2), 93-110. https://doi.org/10.21861/hgg.2011.73.02.07

Ingram, D. R. (1971). The Concept of Accessibility: A search for an operational form. Regional Studies, 5(2), 101107. http://doi.org/http://dx.doi.org/10.1080/09595237100185131

INVAMA. (2013, June 20th). Construcción de intercambiador vial sobre la Avenida Kevin Ángel en el sector de la Carola del municipio de Manizales (INV-L-001-2017). Retrieved from https:/www.contratos.gov.co/consultas/detalleProceso.do?numConstancia=17-1-169254

INVAMA. (2017, October 30th). Ejecución de obras civiles consistentes en la construcción de la intersección fundadores Caldas motor - Av. Colon de la ciudad de Manizales (INV-L-009-2013). Retrieved from https:/www.contratos.gov.co/consultas/detalleProceso.do?numConstancia=13-1-94015

INVAMA. (2018, February). Información general. Retrieved from https://invama.gov.co/proyectos-v/

INVAMA. (2018, January). Elaborar estudios de definición y diseños de las alternativas para el mejoramiento del acceso a los barrios la Francia y los Alcázares (INV-C-002-2018). Retrieved from https:/www.contratos.gov.co/consultas/detalleProceso.do?numConstancia=18-15-7638743

INVIAS. (2017, November 27th). Presidente Santos inauguró intersección la Fuente en Manizales. Retrieved from https://www.invias.gov.co/index.php/mas/sala/noticias/2894-presidente-santos-inauguro-interseccionla-fuente-en-manizales

Karou, S., \& Hull, A. (2014). Accessibility modelling: Predicting the impact of planned transport infrastructure on accessibility patterns in Edinburgh, UK. Journal of Transport Geography, 35, 1-11. http://doi.org/10.1016/j.jtrangeo.2014.01.002

Mitchell, R. B., \& Rapkin, C. (1954). Urban Traffic: A Function of Land Use. Columbia University press, New York.

Monzón de Cáceres, A. (1988). La accesibilidad individual como elemento de evaluación de los planes de transporte en la comunidad de Madrid/España. Informes de la Construcción, 40(396), 21-38. Retrieved from: http://www.ingentaconnect.com/content/doaj/00200883/1988/00000040/00000396/art00002

Olsson, M. (2016). Functional regions in gravity models and accessibility measures. Moravian Geographical Reports, 24(2), 60-70. http://doi.org/10.1515/mgr-2016-0011.

Perilla, D. J., Escobar, D. A., \& Cardona, S. (2018). New Transportation Infrastructure Impact in Terms of Global 
Average Access - Intersection "La Carola" Manizales (Colombia) Case Study. Contemporary Engineering Sciences, 11(5), 215-227. http://doi.org/https://doi.org/10.12988/ces.2018.812

Pirie, G. H. (1979). Measuring Accessibility: A Review and Proposal. Environment and Planning A, 11(3), 299312. http://doi.org/10.1068/a110299

Prasetiyowati, S. S., Imrona, M., Ummah, I., \& Sibaroni, Y. (2016). Prediction of Public Transportation Occupation Based on Several Crowd Spots Using Ordinary Kriging Method. Journal of Innovative Technology and Education, 3(1), 93-104. http://doi.org/http://dx.doi.org/10.12988/jite.2016.6723

Robledo, J. E. (1996). La Ciudad de la colonización Antioqueña. Manizales. Editorial Universidad Nacional de Colombia.

Sallán, J., Suñé, A., Fernandéz, V., \& Fonollosa, J. (2002). Métodos cuantitativos de organización industrial I. Ediciones de la Universidad Politécnica de Catalunya, España, (pp. 159-169).

Shoorcheh, M., Varesi, H., Mohammadi, J., \& Litman, T. (2016). Urban Growth Structure and Travel Behavior in Tehran City. Modern Applied Science, 10(8), 32-47. http://doi.org/10.5539/mas.v10n8p32

Talpur, M. A. H., Napiah, M., Chandio, I. A., \& Khahro, S. H. (2012). Transportation planning survey methodologies for the proposed study of physical and socio-economic development of deprived rural regions: A review. Modern Applied Science, 6(7), 1-16. http://doi.org/10.5539/mas.v6n7p1

Vega, A. (2011). A multi-modal approach to sustainable accessibility in Galway. Regional Insights, 2(2), $15-17$. http://doi.org/10.1080/20429843.2011.9727923

Wackernagel, H. (2003). Multivariate geostatistics: an introduction with applications. Springer Science \& Business Media. Berlin, Alemania.

Weibull, J. W. (1976). An axiomatic approach to tee measuwm1ent of. Regional Science and Urban Economics, 6(4), 357-379. http://doi.org/10.1016/0166-0462 (76)90031-4

\section{Copyrights}

Copyright for this article is retained by the author(s), with first publication rights granted to the journal.

This is an open-access article distributed under the terms and conditions of the Creative Commons Attribution license (http://creativecommons.org/licenses/by/4.0/). 